\title{
Novos Letramentos: perspectivas atuais para o ensino de inglês como língua estrangeira ${ }^{1}$
}

NeW LITERACIES: CURRENT PERSPECTIVES ON TEACHING ENGLISH AS A

FOREIGN LANGUAGE

Andréa Machado de Almeida MATTOS*

Resumo: Os novos letramentos abarcam uma noção de linguagem como prática social (BRANDT; CLINTON, 2002) e a compreensão de que é necessário proporcionar o desenvolvimento do senso crítico dos cidadãos/ alunos (BRASIL, 2006), objetivando a mudança social. Este texto tem por objetivo introduzir as teorias de Novos Letramentos (STREET, 1984; LANKSHEAR; KNOBEL, 2003; BAYNHAM; PRINSLOO, 2009) e sua relevância para pesquisas no campo do ensino de inglês como língua estrangeira e da formação do professor. Para tanto, apresenta e discute um grupo de teorias recentes que servem de fundamentação teórica para uma possível mudança epistemológica no ensino de inglês como língua estrangeira, principalmente em contextos de escola pública.

Palavras-chave: Novos letramentos. Ensino de inglês como língua estrangeira. Formação de professores.

Abstract: The new literacies studies encompass a notion of language as social practice (BRANDT; CLINTON, 2002) and the understanding that it is necessary to foster the development of critical thinking citizens/students

* Doutora em Estudos Linguísticos e Literários em Inglês pela Universidade de São Paulo (2011). Professora Adjunta da Faculdade de Letras da Universidade Federal de Minas Gerais. Contato: andreamattosufmg@gmail.com.

${ }^{1}$ Este trabalho é um recorte de minha tese de doutorado defendida na Universidade de São Paulo, sob a orientação da Prof. ${ }^{a}$ Dr. ${ }^{a}$ Walkyria Monte Mór. Para outras informações sobre o assunto e discussões mais detalhadas de termos e conceitos, ver Mattos (2011a). 
(BRASIL, 2006), aiming at social change. This paper aims to introduce the theories of New Literacies (BAYNHAM; PRINSLOO, 2009; LANKSHEAR; KNOBEL, 2003; STREET, 1984) and its relevance to research in the field of teaching English as a foreign language and teacher education. It presents and discusses a group of recent theories that serve as the theoretical basis for a possible epistemological change in teaching English as a foreign language, especially in public schools.

Key words: New literacies. Teaching English as a foreign language. Teacher education.

\section{Introdução}

O Ensino de Inglês como Língua Estrangeira no Brasil vem sofrendo grandes mudanças, principalmente devido ao imperativo das novas tecnologias, aos processos de globalização e à influência de documentos oficiais recentes, como as Orientações Curriculares para o Ensino Médio Conhecimentos de Línguas Estrangeiras (OCEM-LE) (BRASIL, 2006). A sociedade ocidental atual revela-se altamente letrada e tecnologizada (LANKSHEAR; KNOBEL, 2003), à medida que a tecnologia torna-se quase que onipresente em nossas vidas. Ao mesmo tempo, os processos de globalização vêm trazendo mudanças exponenciais para a sociedade em geral, influenciando também a educação e, por consequência, o ensino de inglês como língua estrangeira (LE) e a formação do professor de línguas. É nesse contexto que surgem as teorias sobre novos letramentos, como uma nova tendência para o ensino de inglês como língua estrangeira na escola regular, a partir de sugestões das OCEM-LE. Os novos letramentos abarcam uma noção de linguagem como prática social e a compreensão de que é necessário proporcionar o desenvolvimento do senso crítico dos cidadãos/alunos, permitindo questionar, analisar e contestar as relações de poder existentes, com vistas a provocar mudança social. Este texto tem por objetivo introduzir as teorias de Novos Letramentos e sua relevância para pesquisas no campo do ensino de inglês como LE e da formação do professor. Para tanto, este texto apresenta e discute um grupo de teorias recentes que servem de fundamentação teórica para uma possível mudança epistemológica no ensino de LE, principalmente em contextos de escola pública. Conhecê-las mais profundamente e esclarecer seus conceitos e características pode auxiliar 
professores em formação inicial ou continuada, e até mesmo formadores de professores, que se veem, hoje, bombardeados por inúmeras propostas metodológicas (JORDÃO; MATTOS; GATTOLIN, 2011) e diferentes políticas públicas federais, estaduais e municipais (DUBOC, 2011; MACIEL, 2011), que muitas vezes lhes causam confusão.

\section{A Noção de Letramento e seus Desdobramentos}

Soares (1998) estabelece uma importante distinção entre os conceitos de alfabetização e letramento. Para a autora, "alfabetizar é ensinar [alguém] a ler (e também a escrever)" (SOARES, 1998, p. 16), e letramento é "o resultado da ação de ensinar ou de aprender a ler e escrever: o estado ou a condição que adquire um grupo social ou um indivíduo como consequência de ter-se apropriado da escrita" (SOARES, 1998, p. 18). No entanto, os processos de letramento vão além da tradicional concepção de alfabetização, compreendida restritamente como a capacidade de decodificação do sistema de escrita. Rojo (2002, p. 32) afirma que "ler envolve diversos procedimentos e capacidades (perceptuais, práxicas, cognitivas, afetivas, sociais, discursivas, lingüísticas), todas dependentes da situação e das finalidades de leitura," as quais são normalmente definidas por práticas localizadas e socio-historicamente (re)produzidas. O conceito de letramento, assim, atualmente, se expandiu e "passou a designar práticas sociais de leitura e escrita" (MATTOS, 2011b).

Vários autores da atualidade discutem o conceito de letramento a partir de diferentes pontos de vista e oferecem definições variadas. Para Street (1984, p. 1), por exemplo, letramento é "um termo-síntese para resumir as práticas sociais e concepções de leitura e escrita”. Já Lemke (1998, p. 1) define letramento genericamente "como um conjunto de competências culturais para criar significados socialmente reconhecíveis através do uso de tecnologias materiais específicas". Norton (2007, p. 6), por sua vez, afirma que a "concepção dominante de letramento entre governantes, criadores de políticas públicas e membros do público geral é que letramento se refere à habilidade, por parte dos indivíduos, de ler e escrever". A autora não defende essa concepção, mas afirma que ela não deixa de ser útil e importante. Lankshear, Snyder e Green (2000) adotam a definição de Street (1984), citada anteriormente, mas observam que letramento não pode ser tomado como algo fixo, pois está sempre em evolução. Mark (2009, p. 108) afirma que "não há nenhuma maneira universalmente eficaz ou culturalmente apropriada 
de [...] definir letramento." Pelo contrário, para o autor, qualquer definição de letramento deve ser vista como uma decorrência das "condições sociais, culturais e econômicas" (MARK, 2009, p. 108) do meio em que foi produzida. Sua definição de letramento, ou "práticas de letramento," é bastante abrangente, podendo integrar "rotinas, habilidades, e concepções que são organizadas em contextos específicos, e também os sentimentos e valores que as pessoas têm sobre essas atividades" (MARK, 2009, p. 120). Vemos, assim, que o letramento tem uma natureza estritamente local e que, por isso, não pode ser concebido de forma universalizante, ou seja, através de definições globais e generalizadoras.

Castell, Luke e MacLennan (1986, p. 6) argumentam que "a abordagem tecnocrata da educação tem dominado a prática e a pesquisa educacional", levando à disseminação e ao uso de práticas de avaliação do letramento escolar através de instrumentos padronizados. Isso, na visão dos autores, é um dos problemas que justificam a percebida "crise do letramento", devido à "discrepância entre o que conta como letramento na escola, e os tipos de letramento real, úteis para a comunidade e para atividades ocupacionais" (CASTELL; LUKE; MACLENNAN, 1986, p. 7). É justamente essa concepção de letramento como algo que atenda às necessidades e demandas do "trabalho e da cidadania na sociedade moderna" que os autores chamam de "letramento funcional", ou seja, uma tentativa de "articular um conceito de letramento que seja relevante para os aspectos mais práticos da vida diária para a sociedade como um todo" (CASTELL; LUKE; MACLENNAN, 1986, p. 7) e não apenas para aquela parcela da sociedade tida como detentora da alta cultura e vista como a "classe letrada" dominante.

Os autores afirmam que o termo "letramento funcional" tem sido amplamente usado em vários contextos e citam a definição do Comitê para Padronização de Estatísticas Educacionais da UNESCO, de 1971, que diz que "uma pessoa é letrada quando já adquiriu o conhecimento e as habilidades essenciais que permitem que ela se engaje em todas aquelas atividades nas quais o letramento é necessário para funcionar efetivamente no seu grupo ou comunidade" (apud CASTELL; LUKE; MACLENNAN, 1986, p. 8). Para os autores, no entanto, definições desse tipo não são suficientes, já que não consideram diferenças individuais quanto aos contextos de uso do letramento.

Por isso, Castell, Luke e MacLennan (1986) apontam algumas questões a serem consideradas para uma melhor compreensão teórica do letramento e para o desenvolvimento de práticas e estratégias de ensino. Na visão dos 
autores, seria necessário levar em consideração “os princípios subjacentes que permitem a um indivíduo selecionar, modificar, e aplicar uma competência de leitura já existente para uma nova tarefa de leitura" (CASTELL; LUKE; MACLENNAN, 1986, p. 9). Segundo eles, isso seria necessário para "permitir que um indivíduo aplique as estratégias de processamento da informação usadas na leitura em outros processos de codificação e decodificação da informação, como a escrita, a fala, e a comunicação não-verbal" (CASTELL; LUKE; MACLENNAN, 1986, p. 9). Outra questão a ser considerada seria a importância dos "contextos sociais e pragmáticos em que a interação lingüística ocorre," já que "a natureza contextual da interação lingüística influencia tanto a aquisição quanto o uso do letramento" (CASTELL; LUKE; MACLENNAN, 1986, p. 9).

Citando Bourdieu (1977), Castell, Luke e MacLennan (1986, p. 10) chegam ao conceito de "competência expandida," definida como "a habilidade de exercer a competência de acordo com as variáveis do contexto social”. Para Bourdieu, o problema "não é a possibilidade de produzir um número infinito de frases gramaticalmente coerentes, mas a possibilidade de usar um número infinito de frases em um número infinito de situações, coerentemente e pertinentemente" (apud CASTELL; LUKE; MACLENNAN, 1986, p. 10). É essa noção de competência expandida que os autores sugerem que deve ser considerada nas pesquisas sobre letramento nas sociedades industrializadas do mundo atual.

A conclusão a que chegam esses autores é, hoje, amplamente aceita nos estudos sobre letramento. Eles argumentam que "o letramento é necessariamente 'situacional' [e] definições operacionais de letramento funcional e critérios para a sua avaliação são sempre culturalmente e historicamente especificados" (CASTELL; LUKE; MACLENNAN, 1986, p. 11). Além disso, afirmam que qualquer definição de letramento funcional deve abranger "não apenas o conhecimento de regras e a habilidade de seguir regras, mas também a capacidade de pensar, raciocinar, e julgar para além das regras sociais existentes" (CASTELL; LUKE; MACLENNAN, 1986, p. 11).

Para Gee (2008, p. 31), qualquer concepção atual de letramento é "inerentemente política, no sentido de que envolve relações de poder entre pessoas". É dentro dessa concepção, que o letramento pode ser visto como uma prática social. Como afirma Soares (1998), ao priorizar a dimensão social do fenômeno letramento, este passa a ser definido como aquilo que "as pessoas fazem com as habilidades de leitura e de escrita, em um contexto 
específico, e como essas habilidades se relacionam com as necessidades, valores e práticas sociais" (SOARES, 1998, p. 72). Nesse sentido, o letramento deixa de ser definido em termos de habilidades individuais e passa a ser, para Soares (1998, p. 72), “o conjunto de práticas sociais ligadas à leitura e à escrita em que os indivíduos se envolvem em seu contexto social".

Soares (1998) relata que essa dimensão social do letramento pode ser interpretada de duas maneiras conflitantes. Segundo ela, há uma versão "fraca" e uma versão "forte" das características e implicações da dimensão social do letramento. Em sua versão "fraca", a definição de letramento corresponde justamente ao que Castell, Luke e MacLennan (1986) chamam de letramento funcional, conforme já discutido. Soares (1998, p. 72) acrescenta que essa concepção de letramento como uma habilidade funcional, ou seja, aquilo que permite que "o indivíduo funcione adequadamente em um contexto social", é uma interpretação progressista e liberal do termo, que carrega em seu bojo

... a crença de que conseqüências altamente positivas advêm, necessariamente, dele: sendo o uso das habilidades de leitura e escrita para o funcionamento e a participação adequados na sociedade, e para o sucesso pessoal, o letramento é considerado como responsável por produzir resultados importantes: desenvolvimento cognitivo e econômico, mobilidade social, progresso profissional, cidadania. (SOARES, 1998, p. 74).

Conforme ressalta Gee (2008), o "mito do letramento", ou a crença de que possuir habilidades letradas produz inúmeras consequências positivas para o indivíduo, hoje em dia está desacreditado, porque "o letramento, por si só, abstraído das condições históricas e das práticas sociais, não tem nenhum efeito ou, pelo menos, nenhum efeito previsível” (GEE, 2008, p. 45). Segundo ele, aquilo que produz essas consequências "são práticas sociais historicamente e culturalmente situadas das quais ler e escrever são apenas pedacinhos que são diferentemente compostos e situados em diferentes práticas sociais" (GEE, 2008, p. 45, grifo meu).

Essa concepção, segundo Soares (1998, p. 74), traduz a versão "forte" da concepção de letramento para a qual o letramento "não pode ser considerado um 'instrumento' neutro a ser usado nas práticas sociais quando exigido". Muito mais que isso, o letramento, nessa concepção, é definido como 
... um conjunto de práticas socialmente construídas que envolvem a leitura e a escrita, geradas por processos sociais mais amplos, e responsáveis por reforçar ou questionar valores, tradições e formas de distribuição de poder presentes nos contextos sociais. (SOARES, 1998, p. 74-75).

A chamada versão "forte" da concepção de letramento deu origem a alguns dos estudos mais profícuos sobre letramento, da forma como é interpretado e compreendido nas pesquisas atuais. Essa nova forma de entender e trabalhar o letramento ficou conhecida como "novos letramentos" e, mais tarde, "multiletramentos", como veremos a seguir.

\section{Novos Letramentos e Multiletramentos}

Larson e Marsh (2005) explicam que, a partir do final dos anos 70 e início dos anos 80, pesquisadores do letramento passaram a descrever as práticas de leitura e escrita como práticas intrinsecamente ligadas às práticas sociais em uso de grupos sociais específicos, desafiando a maneira tradicional de se abordar a leitura e a escrita. Grandes nomes que figuram dentre esses pesquisadores são Shirley Brice Heath (1983) e Brian Street (1984), além do trabalho seminal de Scribner e Cole (1981 apud BAYNHAM; PRINSLOO, 2009), dando início ao que hoje é conhecido como Estudos sobre Novos Letramentos ou New Literacy Studies (BAYNHAM; PRINSLOO, 2009; LARSON; MARSH, 2005). Gee (2008) e Baynham e Prinsloo (2009) afirmam que esses estudos começaram a surgir no início da década de 1990, a partir de pesquisas realizadas em diferentes áreas do conhecimento.

Assim, os estudos sobre novos letramentos surgiram em oposição à visão tradicional, então dominante, de que letramento é um conjunto de habilidades cognitivas ou psicológicas que as pessoas possuem, e que podem ser ensinadas de maneira neutra em contextos formais ou informais de ensino. Para Larson e Marsh (2005), os estudos dos novos letramentos veem o letramento como uma prática social complexa e crítica, construída a partir de interações sociais diárias em contextos específicos.

Tradicionalmente, o letramento foi tratado como uma habilidade individual e o desenvolvimento escolar avaliado através de uma trajetória linear cuidadosamente planejada. Larson e Marsh (2005) afirmam que abordagens tradicionais de ensino acreditam que o letramento é um conjunto 
de habilidades que podem ser ensinadas isoladamente e que a prática individual e repetida dessas habilidades é suficiente para seu aprendizado. Além disso, a prática tradicional do letramento nas escolas segue um modelo linear que, segundo as autoras, introduz conceitos específicos de acordo com estágios específicos do desenvolvimento cognitivo dos aprendizes, principalmente tendo por base sua idade, pois assume que "as crianças progridem de forma semelhante e adquirem habilidades específicas em seqüência" (LARSON; MARSH, 2005, p. 4-5). No entanto, Larson e Marsh (2005, p. 5) afirmam que, nessa abordagem tradicional, as crianças que não conseguem adquirir tais habilidades da forma ou com a rapidez previstas são apontadas como "inadequadas", levando, assim, à criação de um modelo de "déficit".

Larson e Marsh (2005, p. 5) acrescentam que modelos tradicionais de letramento estão associados às crianças que seguem um desenvolvimento dito "normal", ou seja, aquelas que vivem em "famílias que apoiam o desenvolvimento da criança através da provisão de recursos específicos e práticas de letramento". Segundo as autoras, é dessa maneira que as normas e práticas sociais de famílias brancas e de classe média passam a ser reconhecidas como experiências de letramento desejáveis para todas as crianças.

Como observou Gee (2008, p. 51), ao longo de toda a nossa história, o uso da linguagem se constituiu num ponto de identificação entre seres humanos, ou seja, é a linguagem que "nos faz humanos e que nos diferencia de outras criaturas na terra". No entanto, o letramento se tornou um ponto de diferenciação entre os próprios seres humanos, separando os letrados dos não letrados, e atribuindo características específicas - e mais valorizadas culturalmente - aos letrados, como inteligência, modernidade e moralidade, e ligando os indivíduos e culturas letradas à noção de civilização. Mesmo entre indivíduos e culturas letradas, o letramento pode ser tomado como um ponto de diferenciação entre indivíduos se for considerado a partir de pontos de vista tradicionais, ou seja, quando é visto como uma habilidade cognitiva individual que pode ser aprendida de forma isolada e neutra. É nesse sentido que, conforme Larson e Marsh (2005), o letramento pode ser usado para diferenciar a aprendizagem de crianças em idade escolar, levando à discriminação, isto é, à crença na capacidade de algumas dessas crianças em oposição à incapacidade de outras.

Pesquisadores das teorias de novos letramentos, portanto, são contrários a essas práticas tradicionais e advogam modelos de letramento que transferem o foco de compreensão do letramento como uma habilidade cognitiva 
individual para práticas sociais situadas. Para esses estudiosos, o letramento é socialmente construido e abordagens pedagógicas do letramento compreendem e enfatizam a natureza social da aprendizagem e a importância das comunidades discursivas que se estabelecem nas salas de aula, encarando a aprendizagem como pequenas modificações na forma de participação dos aprendizes $^{2}$. Dessa forma, como afirma Gee (2008, p. 67), os estudos sobre novos letramentos "começaram a substituir a noção tradicional de letramento por uma abordagem sociocultural." Como o letramento passou a ser visto como um "conjunto plural de práticas sociais", os pesquisadores passaram a se referir, então, a letramentos, no plural.

Com o advento das novas tecnologias de informação e comunicação, um grupo de pesquisadores passou a trabalhar com a ideia de multiletramentos e chamou "a atenção de educadores para as maneiras com que modos comunicativos estavam proliferando e se modificando devido aos avanços na tecnologia" (LARSON; MARSH, 2005, p. 3). Esse grupo se reuniu pela primeira vez em 1994, na cidade de New London, em New Hampshire, nos Estados Unidos, e por isso ficou conhecido como The New London Group (COPE; KALANTZIS, 2000). Dentre esses pesquisadores figuram nomes como Bill Cope, Norman Fairclough, James Gee, Mary Kalantzis, Gunther Kress e Alan Luke, por exemplo. Esses pesquisadores começaram a mostrar como a tecnologia passou a transformar as bases ontológicas e epistemológicas do letramento, criando novas práticas sociais e influenciando seus contextos.

Segundo Cope e Kalantzis (2000, p. 5), esse grupo escolheu a palavra "multiletramentos" para resumir os resultados de suas discussões devido a dois argumentos: "a multiplicidade de mídias e canais de comunicações e a crescente saliência da diversidade lingüística e cultural”. O primeiro argumento, segundo os autores, diz respeito à "multiplicidade crescente e à constante integração de importantes modos de construção de significado", onde os modos textual, audiovisual, espacial e comportamental estão intimamente imbricados, ou seja, na sociedade de hoje, o significado é criado de maneira

${ }^{2}$ Larson e Marsh (2005, p. 10) explicam essas pequenas modificações na participação dos aprendizes, o que elas chamam de "learning as changing participation", como modificações que ocorrem ao longo do tempo à medida que crescem as habilidades e o expertise dos participantes do contexto, e afirmam que "as pessoas aprendem através da participação em atividades culturalmente valorizadas". 
cada vez mais multimodal. O segundo argumento diz respeito à nova realidade imposta pelos processos de globalização que apontam para uma "crescente diversidade local" ao mesmo tempo em que exige "conectividade global" e, por isso, "precisamos negociar diferenças todos os dias, em nossas comunidades locais e em nossas vidas profissionais e comunitárias cada vez mais globalmente interconectadas" (COPE; KALANTZIS, 2000, p. 6). Para os autores, esses dois pontos - a multiplicidade dos modos de construção de significado e o aumento da diversidade local conjugada à conectividade global - podem potencialmente transformar tanto as práticas de letramento presentes em nossa sociedade atualmente quanto as pedagogias para o letramento, o que exige que tanto educadores quanto educandos assumam papéis ativos que almejem à mudança social.

Assim, a concepção de multiletramentos complementa e suplementa a noção tradicional de letramento, centrada apenas na língua nacional enquanto monolítica, singular e estável. Em oposição a essa visão tradicional de língua, a concepção de multiletramentos se centra em outros modos de representação que não apenas a linguagem, e que podem variar conforme o contexto e a cultura do grupo social em questão.

Os novos letramentos e multiletramentos estabeleceram-se, assim, como perspectivas inovadoras para compreensão das práticas de letramento hoje presentes na sociedade globalizada do século XXI. Os pesquisadores atualmente envolvidos nesses estudos tomam por base a noção de que essas práticas de letramento não são individuais, mas sim sociais, ou seja, são compartilhadas por comunidades e grupos sociais específicos e, por isso mesmo, são plurais.

\section{Modelos de Letramento}

De acordo com Street (1984), é possível distinguir basicamente dois modelos de letramento que são atualmente usados em várias disciplinas: o modelo autônomo e o modelo ideológico. No modelo autônomo, o letramento é visto como "uma tecnologia neutra que pode ser separada de contextos sociais específicos" (SOARES, 1984, p. 1). Os teóricos que defendem essa concepção acreditam que o letramento tem um papel central no desenvolvimento da competência intelectual dos indivíduos e que a aprendizagem de formas especializadas de escrita causa um impacto significativo na linguagem e no pensamento. Para esses teóricos, sociedades 
letradas, ou seja, aquelas que já se apropriaram da cultura escrita, e sociedades de cultura oral diferem significativamente umas das outras devido a "diferenças fundamentais entre a linguagem oral e a escrita" (SOARES, 1984, p. 20). Segundo Street (1984, p. 20), nessa concepção, “a linguagem oral é sempre direcionada a um indivíduo particular normalmente com algum efeito pretendido, como influenciar seu ponto de vista, manter um certo relacionamento ou controlar suas ações". Além disso, esse tipo de linguagem também "pode ser constantemente modificada de acordo com seus efeitos e por isso a função social domina a função lógica” (STREET, 1984, p. 20), mas para isso necessita de apoio concreto na realidade, como nas interações face a face em que o falante modifica suas proposições de acordo com as reações do ouvinte. A linguagem escrita, por outro lado, "torna tais funções interpessoais menos críticas; pode ser conduzida através do tempo e do espaço e está menos sujeita ao feedback imediato" (STREET, 1984, p. 20).

$\mathrm{O}$ autor explica, ainda, que, para esses teóricos, "a linguagem oral depende do contexto para transmitir significado [e] por isso é egocêntrica e assume um ponto de vista comum como se nenhum outro fosse possível" (STREET, 1984, p. 21). Afirma que esses autores acreditam que a palavra escrita possui certas "qualidades inerentes" que permitem o desenvolvimento cognitivo dos indivíduos que dela se apropriam, como, por exemplo, a capacidade de permitir a abstração e de estar menos conectada com o aqui e o agora, além de permitir o "desenvolvimento da lógica, a distinção entre mito e história, a emergência do pensamento e de instituições científicas e até o crescimento de processos políticos democráticos" (STREET, 1984, p. 5).

Devido a essas diferenças entre a linguagem oral e a linguagem escrita, os autores partidários do modelo autônomo defendem que "membros de sociedades letradas tem a possibilidade de desenvolver funções lógicas, de se especializar nas 'funções reais' da linguagem e de se distanciar do aqui e agora da vida social diária," como explica Street (1984, p. 20). Nas sociedades letradas, portanto, os indivíduos teriam a possibilidade de adquirir, através da escolarização e do letramento, hábitos abstratos de pensamento, o que seria impossível em sociedades de cultura oral. A consequência natural do desprovimento da escrita nas culturas orais, para esses autores, seria uma diminuída capacidade intelectual dos indivíduos, em relação aos indivíduos de culturas letradas. O letramento, assim, seria responsável por diferenças cognitivas significativas entre os dois tipos de sociedade. 
Street (1984), no entanto, combate os argumentos desses teóricos e afirma que eles estariam promovendo uma nova versão da chamada 'great divide', ou seja, a divisão clássica das sociedades em termos de critérios como lógicas/pré-lógicas, primitivas/modernas e concretas/científicas, para acrescentar um novo critério: letradas/pré-letradas. Argumenta que há evidência da existência de

... pensamento científico e não-científico em todas as sociedades e em todos os indivíduos [e que] representações de inferioridade cognitiva [nas culturas orais] são fundamentadas na incompreensão dos significados reais da fala e das ações das pessoas, e em pressuposições etnocêntricas sobre as maneiras como a lógica pode ser reconhecida. (STREET, 1984, p. 26).

Contrapondo os argumentos dos defensores do modelo autônomo do letramento, Street (1984, p. 26) afirma que apenas "o fato de falar uma língua já é por si empregar abstração e lógica”. Pondera que a ideia de que o letramento promove o desenvolvimento das funções lógicas da linguagem não pode ser tomada de forma absoluta, já que "as conseqüências [do letramento] dependem do papel social, das funções e dos significados de suas práticas" (STREET, 1984, p. 41).

O modelo autônomo, como discutido, defende que certas habilidades tidas como "corretas" são necessárias para que o indivíduo atinja maior desenvolvimento cognitivo e econômico, progresso profissional e, consequentemente, mobilidade social. São essas habilidades que devem ser ensinadas através do letramento. Trazendo essas ideias para o ensino de inglês como língua estrangeira, podemos dizer que, tradicionalmente, várias abordagens de ensino já usadas ao longo da história se identificam com o modelo autônomo descrito por Street (1984), como, por exemplo, a tradução e o Método Audiolingual. Nessa abordagem, a repetição mecânica na forma de drills seria a responsável por produzir correção ou um padrão linguístico ideal, gerando autoconfiança no aprendiz que, então, se incumbe da transferência de seu aprendizado para as situações de vivência social. Verificou-se, no entando, que as formas repetidas à exaustão durante as aulas de inglês durante os anos 60 e 70 - período áureo do audiolingualismo no Brasil e no mundo - dificilmente podiam ser transpostas para contextos reais, principalmente porque os contextos pedagógicos distanciavam-se em 
muitos casos do contexto de uso do aluno. Essa abordagem, porém, continua a ser usada ainda hoje em muitos contextos de ensino de inglês como língua estrangeira (MATTOS; VALÉRIO, 2010), juntamente com outras práticas tradicionais, como a tradução, conforme indicam dados de pesquisa realizada com três professores de inglês de escola pública da Região Metropolitana de Belo Horizonte (MATTOS, 2011a) que admitem, em momentos diferentes, já terem usado ou ainda usarem a tradução em suas salas de aula, como forma de garantir a compreensão dos alunos. Maurício, por exemplo, um dos participantes da pesquisa, costumava usar atividades de leitura e tradução com frequência com seus alunos de $5^{\mathrm{a}}$ série do ensino fundamental com o objetivo de garantir que eles entendessem o texto que estava sendo usado em sala de aula. No excerto abaixo, Maurício conta por que pediu aos alunos para traduzirem uma pequena história em quadrinhos. Primeiramente, ele diz que pediu a tradução porque os alunos fariam uma prova sobre o texto. Depois, ele assume que pediu a tradução do texto porque precisava de tempo para corrigir os cadernos dos alunos.

M: Aí eles tiveram que copiar do quadro... Primeiro, eu mostrei como que é pra eles. Aí eles copiaram.

P: Humhum. [...] Aí você pediu para eles fazerem a tradução em casa?

M: Eu dei as aulas para eles traduzirem. Muitos não têm dicionário.

P: Ah, tá, então você deixou eles fazerem a tradução em sala.

M: É, em sala. Isso.

P: Mas por que você pediu para eles fazerem tradução?

M: Ah, é que eu pensei assim, como eles vão fazer a prova, eu pensei assim, pra ver como que...

P: Você acha que eles não entenderam o texto?

M: Não, eles lendo sozinhos eles não iam entender, não.

P: Não entendem, não?

M: Não. Com certeza não.

P: Nem com a ajuda das figuras?

M: É. Eu fiz essa experiência. Eu fui tentando... Eu peguei a historinha, e fui perguntando pra eles. O que que eles acharam de acordo com a ... com a gravura. Até que teve turma que conseguiu. Aí depois eu... Aí depois eu entrei com a tradução.

$[\ldots]$ 
M: Mas, igual eu estava comentando com Dora. Eu gostei da tradução deles. Assim, porque a gente depois fez correção coletiva, entendeu? Eles conseguiram, direitinho.

$[\ldots]$

M: Outra coisa que me levou a fazer isso também: eu tinha que olhar os cadernos. Então, enquanto eles estavam fazendo a tradução eu já fui aproveitando para dar visto nos cadernos.

(Reunião de grupo de pesquisa-ação colaborativa) $^{3}$

Como apreendemos do excerto, Maurício parece não confiar na capacidade de seus alunos para compreender um texto a partir de dicas, ou informações não verbais, como é o caso das imagens da história em quadrinhos. No entanto, ele mesmo revela que algumas turmas foram capazes de compreender o conteúdo do texto com a ajuda das imagens. Mesmo assim, ele pediu que todos os alunos fizessem a tradução escrita do texto, enquanto ele corrigia os cadernos. Isso revela que a visão de Maurício sobre o que é saber uma língua estrangeira está ainda arraigada na ideia de saber a lingua, ou seja, compreender as palavras, independentemente de qualquer outro recurso que possa ser usado para ajudar a compreensão, como seria o caso numa visão a partir das teorias de novos letramentos. Infelizmente, como indicam alguns trabalhos recentes na área de formação de professor (conforme já citado), Maurício não é um caso isolado no contexto brasileiro, nem tampouco foi o único participante da pesquisa a fazer uso da tradução. As outras participantes - Dora e Cris - também se utilizaram da tradução em sala de aula. Dora, por exemplo, comenta que, antes de mudar sua maneira de ensinar, queria que seus alunos fossem "excelentes tradutores" e diz que os professores, incluindo-se entre eles, apenas "estão preocupados em ensinar regras gramaticais e tradução.” Cris, por sua vez, ao comentar uma das atividades que desenvolveu com seus alunos, relata que escreveu no quadro algumas questões para discussão e que traduziu cada questão antes de deixar que os alunos as discutissem em grupos, como forma de garantir que todos tivessem compreendido. Isso mostra que esses professores ainda têm como visão de aprendizagem de língua a concepção de que para saber uma língua

${ }^{3}$ Convenções de transcrição: $\mathrm{M} \rightarrow$ Maurício (participante); $\mathrm{P} \rightarrow$ Pesquisadora; [...] $\rightarrow$ Comentários não relevantes para o ponto em questão. 
estrangeira é necessário ter certeza do significado de cada palavra usada, independentemente do contexto de uso, uma visão mecanicista que se coaduna com as concepções do modelo autônomo de letramento.

Com o passar do tempo, e devido aos interesses de dominação de várias sociedades, a cultura escrita se estabeleceu como predominante em várias partes do mundo. Street (1984, p. 60) explica que em muitas culturas letradas, a predominância da linguagem escrita pode ser explicada devido às "importantes funções que a escrita realiza nessas sociedades" e, por isso, a escrita possui um maior prestígio social. Em sua análise, Street (1984) novamente cita vários autores que defendem que a linguagem escrita é dotada de maior objetividade e que permite que o escritor se dirija ao leitor sem revelar status ou outras marcas sociais. Street (1984) combate a neutralidade da linguagem escrita e afirma que tanto a maneira como uma pessoa fala quanto o conteúdo daquilo que fala podem revelar marcas sociais. $\mathrm{O}$ autor usa a língua inglesa como exemplo e demonstra que vários recursos amplamente utilizados pela chamada "linguagem acadêmica" para expressar neutralidade e objetividade, como o uso de pronomes impessoais (por exemplo, 'one'), certas escolhas lexicais e estruturas gramaticais (como a vOZ passiva), na verdade são marcas contundentes de status e atitudes, estão imbuídas de poder e, portanto, não podem ser consideradas neutras e/ou objetivas. Pelo contrário, essas escolhas revelam que a linguagem, tanto oral quanto escrita, é socialmente condicionada e transmite uma determinada visão de mundo. Segundo Street (1984), cada língua transmite uma visão de mundo específica que, por isso mesmo, nunca é neutra nem objetiva, e nenhuma língua é capaz de uma objetividade que pode ser tomada como universal. Assim, diferentes línguas seriam capazes de expressar diferentes graus de subjetividade e, por outro lado, "todas as línguas têm o potencial para fazer frases abstratas, relativamente neutras, quando necessário” (STREET, 1984, p. 80). Afirma Street $(1984$, p. 84$)$ que a alegada maior objetividade intrínseca da escrita pode estar baseada em "crenças socialmente construídas sobre o que o letramento pode atingir". Portanto, deve-se sempre considerar o contexto, preocupando-se com o propósito de uma frase específica e o local em que está inserida.

Street (1984, p. 85) acrescenta, também, que “o significado não está simplesmente dentro da frase". É preciso considerar também os participantes e a intersubjetividade destes para entender o significado das frases numa interação, sem deixar de lado questões como "quem controla o significado e 
a natureza da referência" numa dada relação comunicativa (STREET, 1984, p. 85$)^{4}$.

Da mesma forma, em relação à escrita, o autor defende que não há 'significado literal', aquele que seria considerado neutro e isolável de qualquer contexto. Para Street (1984), desmistificar o valor da escrita nas sociedades letradas significa perceber que qualquer sistema escrito está profundamente contaminado pelas restrições culturais, econômicas e tecnológicas da sociedade a que pertence e onde foi gerado, e seu significado depende das situações sociais em que é usado, dos participantes dessas situações sociais e dos propósitos que os guiam. Afirma, ainda, que diferentes culturas desenvolvem diferentes convenções para a escrita e que cada cultura elege diferentes características da escrita como as mais significativas. Para Street (1984), portanto, esses processos deram origem a uma grande variedade de diferentes letramentos.

Para contrapor-se ao modelo autônomo, Street (1984, p. 8) propõe como alternativa o que ele chamou de modelo ideológico ou "modelo de práticas sociais", que "assume que o significado do letramento depende das instituições sociais em ele está inserido” e que “as práticas específicas de leitura e escrita que são ensinadas em qualquer contexto dependem de aspectos da estrutura social tais como estratificação [...] e o papel das instituições educacionais". O autor acrescenta que os usos que diferentes sociedades fazem do letramento estão baseados em convenções e, por isso mesmo, não são universais, nem podem ser definidos em termos de habilidades técnicas, como concebido pelo modelo autônomo.

À concepção de que o letramento leva ao progresso da sociedade, instaura a civilização, facilita a liberdade individual e permite a mobilidade social, premissa básica do modelo autônomo, Street (1984, p. 100) denomina “o mito do letramento", numa alusão ao livro de Harvey J. Graff, historiador social que questiona tal entendimento. Street (1984, p. 104) acredita que “já que a introdução do letramento [em qualquer sociedade] é sempre acompanhada pela introdução de novas formas de organização social, diferenças nos processos de pensamento não podem ser atribuídas ao letramento per se". Street (1984, p. 105) argumenta, então, que "[um] maior

${ }^{4}$ Ver Mattos (2013) para um exemplo sobre os possíveis significados de uma frase, em inglês, em diferentes situações comunicativas. 
letramento não se correlaciona com aumento de igualdade e democracia nem com melhores condições para a classe trabalhadora. Ao contrário, correlaciona-se com a continuação da estratificação social."

Street (1984, p. 106) conclui que o letramento, da forma como é praticado e aprendido na escola, não é um fator suficiente para "superar características imputadas enraizadas na idade, no gênero e na raça”. A educação, assim, presta-se mais às classes dominantes, como uma forma de reprodução de seus valores e de controle social, do que como forma real de progresso e mobilidade para as classes menos privilegiadas. Monte Mór (2009, p. 184) acrescenta que "a prática aparentemente neutra age ideologicamente em favor de uma educação em que os professores são vistos como portadores do conhecimento" e ressalta que "uma prática orientada para a técnica por si carece de uma abordagem crítica que frequentemente é reprimida por seus objetivos reproducionistas".

Street (1984) relata que a introdução do letramento nas sociedades modernas não ocorreu de forma abrupta, pela supressão das práticas orais e imediata substituição destas por práticas escritas. Pelo contrário, essa introdução foi lenta e gradual, e foi facilitada pela mistura dos modos oral e escrito e por uma transição gradual que permitiu a adaptação das formas de escrita às já conhecidas práticas orais. A mistura dos modos oral e escrito, nessa época, era essencial para a sobrevivência da cultura e, até hoje, essa mistura está presente em nossa sociedade. Como exemplifica Street (1984), isso pode ser verificado no uso de convenções internacionais para sinalizar o tráfego nas estradas, uma prática que quase não faz uso de palavras escritas, mas sim de ícones e símbolos. Segundo o autor, "isso não é meramente um gesto em favor daqueles denominados 'iletrados' mas sim um reconhecimento de que a comunicação opera através de modos 'mistos' para todos, sejam 'letrados' ou não" (STREET, 1984, p. 110).

No entanto, o uso dessas convenções internacionais nem sempre está livre de conflitos, comumente gerados pelas diferenças entre percepções culturais globalizadas e os usos e culturas locais das comunidades onde as convenções são usadas. Como exemplo, nos países da América do Norte, principalmente os Estados Unidos e o Canadá, é comum encontrarmos placas indicando "animais na pista" com o símbolo de um cervo, animal comumente encontrado naquela região, como mostra a Figura 1, a seguir. 
Figura 1 - Placa sinalizando "animais na pista” em área urbana, na cidade de Winnipeg, no Canadá

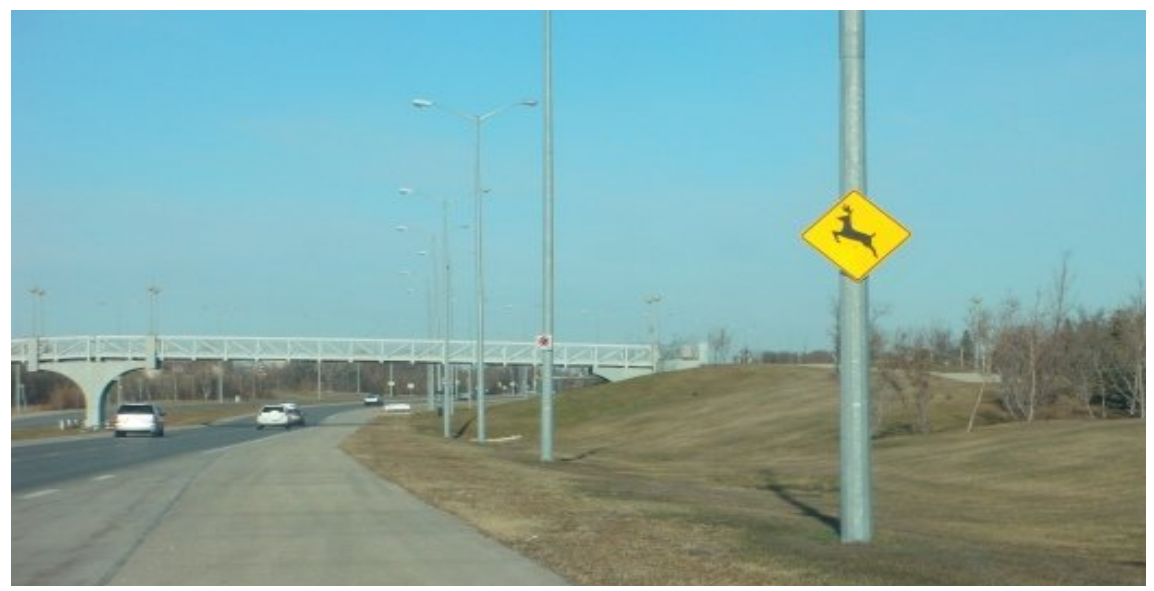

Fonte: Arquivo pessoal da autora.

Esse símbolo tornou-se uma convenção internacional e é usado em vários países do mundo, inclusive no Brasil, onde esse animal não é comumente encontrado nas grandes cidades. O Manual Brasileiro de Sinalização de Trânsito ${ }^{5}$ (BRASIL, 2007), que dispõe sobre as várias placas que devem ser usadas em território nacional para sinalização de advertência para os motoristas, determina que esse símbolo seja usado nas vias públicas brasileiras, como vemos na Figura 2, que reproduz parte da lista de sinais de advertência do manual.

Contudo, como já dito, o animal que simboliza a presença de animais selvagens nas vias públicas brasileiras - o mesmo cervo usado em outros países - não é um animal de fácil reconhecimento para os motoristas brasileiros. Mesmo assim, o símbolo é utilizado em todo o território nacional, tanto em áreas não urbanas quanto nas grandes cidades, como mostram as Figuras 3 e 4.

${ }^{5}$ Aprovado pela Resolução no. 243, de 22 de junho de 2007, do Conselho Nacional de Trânsito (CONTRAN). 
Figura 2 - Reprodução de parte da lista de sinais de advertência do Manual Brasileiro de Sinalização de Trânsito

\begin{tabular}{|l|l|l|}
\hline Sin & A-35 & Animais \\
\hline & A-36 & Animais selvagens \\
\hline
\end{tabular}

6 Índice dos Sinais de Advertência

Fonte: Brasil, 2007.

Figura 3 - Exemplo de sinalização de advertência de "animais na pista" em área não urbana, no Brasil ${ }^{6}$

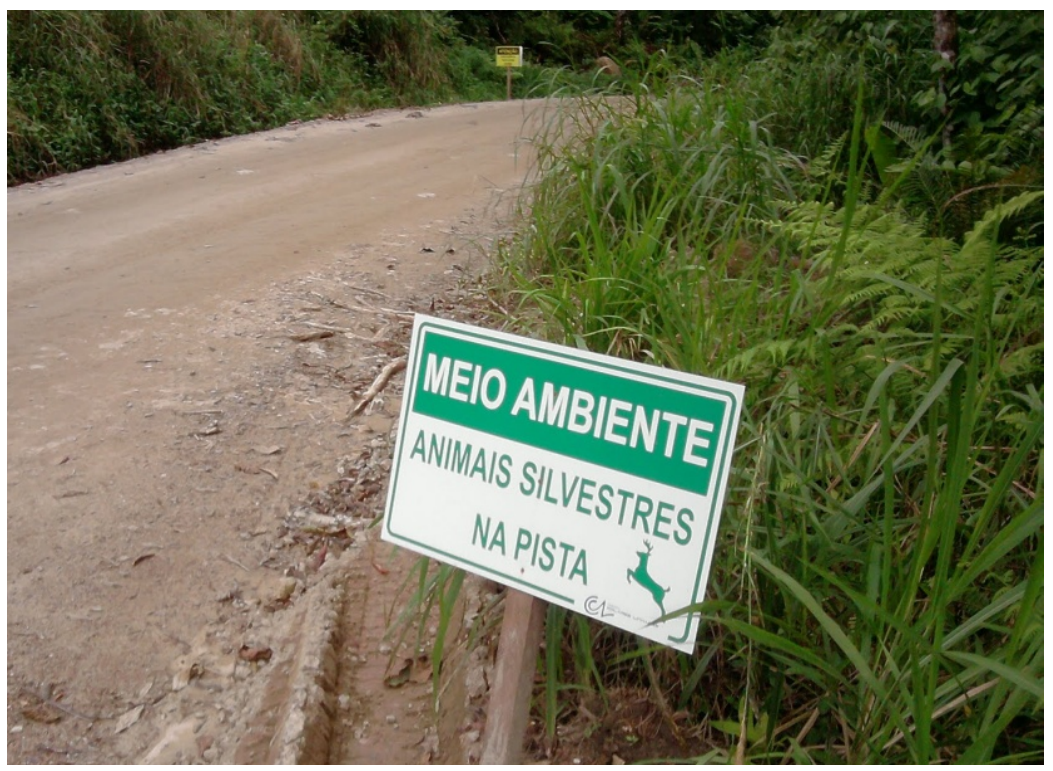

${ }^{6}$ Figura disponível em <http://bikeblogsjc.blogspot.com/ 2010_08_01_archive.html>.Acesso em: 13 dez. 2010. 
Figura 4 - Exemplo de sinalização de advertência de "animais na pista" em área urbana, no Brasil ${ }^{7}$

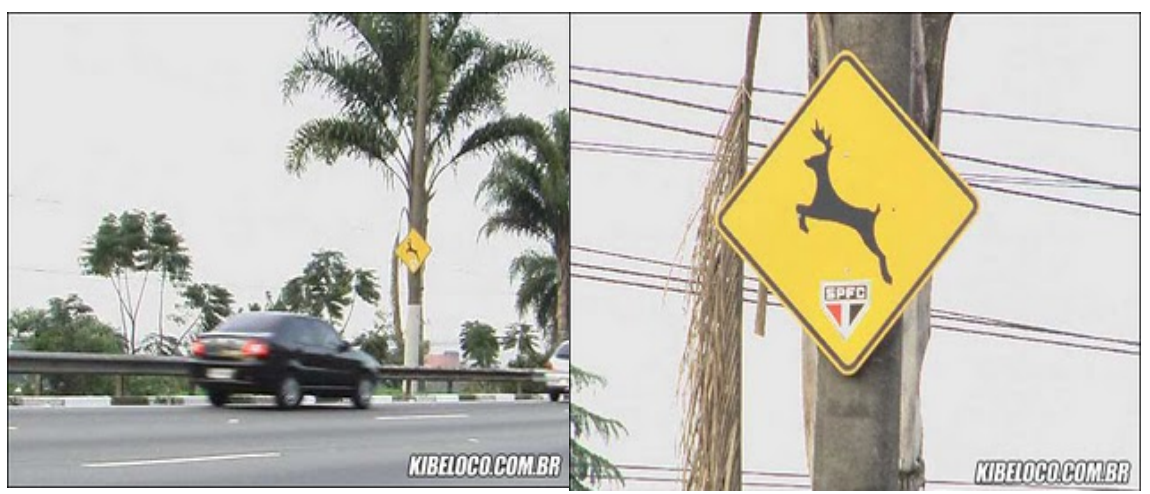

O avanço gradual das formas de letramento, segundo Street (1984), resultou da interação de condições sociais específicas que permitiram a construção de novas práticas sociais baseadas na escrita. Durante esse processo gradual de avanço do letramento, as mudanças ocorridas eram relativamente pequenas e frequentemente não eram notadas pelos participantes da comunidade. Contudo, foram essas pequenas mudanças que facilitaram todo o processo maior que instituiu as mudanças fundamentais para o desenvolvimento da sociedade letrada, da forma como a conhecemos hoje.

Street (1984, p. 121) relembra que sempre que falamos de letramento estamos necessariamente nos referindo "à ideologia e às instituições e formas sociais concretas que dão significado a qualquer prática específica de leitura e escrita". Street (1984) afirma que formas de fazer sentido são sempre aprendidas, sejam formas de fazer sentido de livros ou de comer, sentar, etc., e por isso nunca são neutras, já que são culturalmente determinadas. Crianças de classes sociais superiores, por exemplo, aprendem a fazer sentido de livros muito antes de iniciarem sua vida escolar. O trabalho de Heath (1982, p. 121-122) mostra que essas crianças aprendem "através de histórias para dormir uma infra-estrutura de práticas pedagógicas e pressuposições culturais

${ }^{7}$ Figura disponível em <http://bikeblogsjc.blogspot.com/ 2010_08_01_archive.html>.Acesso em: 13 dez. 2010. 
que combina, em grande parte, com aquelas que elas encontram nas escolas", o que as coloca em vantagem frente a crianças que não passam por esse treinamento familiar ou cujo treinamento é diferente. Street (1984) sugere, então, que essas diferenças culturais na atitude das famílias de crianças em idade pré-escolar podem ser responsáveis, pelo menos em parte, pelo sucesso ou insucesso escolar de crianças de diferentes comunidades ou classes sociais.

As concepções de Street (1984) sobre o modelo autônomo e o modelo ideológico de letramento certamente são importantes, na medida em que ajudam a compreender a noção de letramento e a formar um conjunto de teorias que hoje embasam grande parte das pesquisas sobre o assunto. Não podemos deixar de mencionar, porém, que separar as práticas de letramento ou suas definições em modelos fixos, como fez Street (1984), isolando-as de forma binária, ao mesmo tempo em que contribui para uma exposição didática dos dois modelos, também mostra como eles se confrontam, posicionando-os em lados opostos. Essa maneira fixa de perceber as práticas de letramento e suas concepções deixa de considerar que ambos os modelos estão arraigados nas práticas sociais de qualquer atividade humana, ou seja, mesmo aqueles que acreditam ser o letramento um conjunto de habilidades neutras com objetivos funcionais estarão, necessariamente, perpetuando algum tipo de ideologia e, em contrapartida, aqueles que utilizam o modelo ideológico de letramento sempre estarão também desenvolvendo habilidades funcionais em suas práticas. Pode ser mais apropriado, então, conceber as práticas de letramento, não em termos de modelos binários com polos fixos e opostos, mas em termos de um contínuo, em que práticas ideológicas e habilidades funcionais se misturam e se sobrepõem, ora predominando estas, ora aquelas, o que parece refletir um quadro mais condizente com a complexidade e a fluidez das práticas de letramento de qualquer sociedade moderna.

\section{Letramento como Prática Social}

Como vimos, o letramento não pode ser compreendido de forma neutra, mas deve ser sempre considerado como situado nas práticas sociais de uma determinada comunidade. Soares (1998, p. 72) explica que, assim, o letramento deve ser definido como aquilo que "as pessoas fazem com as habilidades de leitura e de escrita, em um contexto específico”, ou seja, letramento está ligado à maneira, ou maneiras, como os indivíduos de uma determinada comunidade exercitam, no dia a dia, suas habilidades de leitura e escrita. 
Larson e Marsh (2005) afirmam que a concepção de letramento como prática social surgiu de estudos do campo da sociologia do conhecimento que dão suporte à ideia de que a realidade é socialmente construída. As autoras esclarecem que, segundo essa visão, tanto o conhecimento quanto a realidade se constituem em processos dialéticos e contínuos de construção e reconstrução de visões de mundo que os indivíduos e os grupos sociais realizam em interação com a sociedade. Segundo as autoras, "essas visões de mundo são mediadas pela linguagem e pela cultura num processo contínuo de construção da identidade" (LARSON; MARSH, 2005, p. 10).

Assim, as concepções de letramento e do que é possível fazer com o letramento também são construídas nas práticas diárias de cada sociedade. Nesse sentido, Street e Lefstein (2007, p. 42) afirmam que

... a maneira como professores e alunos interagem é uma prática social que afeta a natureza do letramento que está sendo aprendido e as idéias sobre letramento que os participantes possuem, especialmente os novos aprendizes e suas posições nas relações de poder.

Portanto, para eles, o letramento é parte das relações de poder existentes na sociedade.

Brandt e Clinton (2002) chamam a atenção para as diferenças entre os termos "evento de letramento" e "prática de letramento", dois termos importantes que marcam a história das teorias sobre novos letramentos. Evento de letramento foi introduzido por Heath (1983, p. 196), que o definiu como uma "ocasião em que algo escrito integra a natureza das interações dos participantes e suas interpretações de significado”, e Street (1984, p. 1) referiu-se a práticas de letramento como uma maneira de focalizar as "práticas sociais e concepções de leitura e escrita" de uma determinada comunidade. Diferenciando os dois termos, Brandt e Clinton (2002) dizem que um evento de letramento é uma ação social que acontece em torno de um texto escrito que influencia na maneira como as pessoas interagem, e uma prática de letramento é um "conceito mais abstrato, normalmente tratado como as coisas padronizadas, recorrentes e socialmente reguladas que as pessoas fazem com o letramento, assim como o significado cultural atribuído a essas ações"

8 Tradução dos termos originais "literacy event" e "literacy practice." 
(BRANDT; CLINTON, 2002, p. 342). Para as autoras, eventos de letramento constituem ações observáveis, enquanto práticas de letramento são mais abstratas e nem sempre são observáveis.

Para Barton (1994, p. 34), letramento é uma "atividade social e pode melhor ser descrito em termos das práticas de letramento de que as pessoas se utilizam nos eventos de letramento". Barton (1994) acredita que os eventos de letramento estão inseridos em nossas atividades mentais e são formados por nossa consciência, nossas intenções e nossas ações. Além disso, para ele, "qualquer evento de letramento tem uma história, tanto no nível pessoal quanto no nível cultural” (BARTON, 1994, p. 35), já que esses eventos são construídos a partir de eventos passados registrados em nossas histórias individuais e sociais. Alguns exemplos de eventos de letramento são, segundo Barton (1994, p. 36), um adulto lendo uma história para uma criança, um homem discutindo o conteúdo de uma notícia de jornal com um amigo ou tomando nota de um recado para seu filho. Eventos de letramento podem ou não estar ligados a situações que envolvem aprendizagem do letramento.

O autor discute, também, a noção de práticas de letramento que, para ele, são "as práticas sociais associadas à palavra escrita" (BARTON, 1994, p. 37). O autor esclarece que as práticas de letramento constituem os vários eventos de letramento que ocorrem no nosso dia a dia. Em cada evento de letramento, fazemos uso de várias práticas de letramento desenvolvidas e/ou aprendidas durante nossa experiência a partir do conjunto de práticas sociais de nossa cultura. No exemplo em que o adulto lê uma história para uma criança, citado anteriormente, ambos podem fazer uso de várias práticas de letramento típicas de sua cultura durante esse evento de letramento: por exemplo, o adulto pode perguntar à criança o que ela acha que vai acontecer em seguida, a criança pode responder ou pode perguntar o significado de uma determinada frase que ela não compreendeu. Todas essas práticas, e outras que poderiam ocorrer, constituiriam as práticas de letramento ocorridas durante o citado evento de letramento. Para Barton (1994), ver as práticas de letramento a partir do ponto de vista dos eventos de letramento que ocorrem em nosso dia a dia e compreender como elas são aprendidas e reproduzidas a partir do conjunto de nossas práticas sociais pode ajudar a compreender "como as instituições sociais e as relações de poder que elas embasam estruturam nossos usos da linguagem escrita” (BARTON, 1994, p. 37).

Da mesma forma, Barros (2009) afirma que práticas sociais são sempre perpassadas por práticas de linguagem, as quais, por sua vez, se configuram 
em termos de gêneros textuais. Marcuschi (2007, p. 23) explica que os gêneros textuais são "realizações lingüísticas concretas definidas por propriedades sócio-comunicativas”, como o conteúdo, as propriedades funcionais e o estilo, dentre outras. Podemos definir, então, a sala de aula de inglês como língua estrangeira como um evento de letramento que, pelo menos em tese, envolve uma situação de aprendizagem do letramento e que possui, portanto, suas próprias práticas de letramento socialmente construidas ao longo da história do ensino de línguas no Brasil e no mundo.

\section{Conclusão: os novos letramentos e o ensino de inglês como língua estrangeira}

É comum que professores de inglês como língua estrangeira se baseiem em diferentes gêneros textuais para elaborar atividades a serem usadas em suas salas de aula. Assim, essas atividades de ensino caracterizam-se como práticas de linguagem, inseridas nas práticas sociais de ensino de inglês na escola regular, sendo, portanto, práticas de letramento. Essas práticas de letramento seriam, então, as maneiras como os professores utilizam diferentes gêneros textuais e atividades de linguagem para ensinar inglês em seus contextos sociais, ou seja, suas salas de aula na escola regular. Esses professores, no entanto, seguem diferentes práticas de letramento que se coadunam, em sua maioria, com práticas mais tradicionais, dentro de uma perspectiva de letramento funcional ou como ferramenta neutra, ou seja, a aprendizagem da língua inglesa é vista como uma habilidade técnica que pode ser ensinada homogeneamente, sem levar em consideração as heterogeneidades de cada contexto de ensino e as especificidades sociais, históricas e culturais de cada aprendiz. As dificuldades de aprendizagem dos alunos são consideradas, nesses casos, deficiências cognitivas e pessoais de cada aprendiz, a quem é imputada a culpa pela não aprendizagem. Essa visão exime o sistema escolar de qualquer responsabilidade pelas dificuldades enfrentadas por grupos específicos de alunos, criando o modelo de "déficit" (LARSON; MARSH, 2005), como discutimos.

Tais práticas há muito têm levado professores e outros membros da comunidade escolar a separarem alunos em lados opostos da sala de aula, em termos de bons alunos ou maus alunos, bem-sucedidos ou malsucedidos, com aptidão ou sem aptidão, motivados ou desmotivados, dentre outras concepções, todas elas amplamente estudadas por pesquisas que se preocupam 
em decifrar as características individuais dos aprendizes que contribuem para o sucesso na aprendizagem de língua, sem contudo levar em consideração as características sociais e históricas que também influenciam nesse processo.

Além disso, como pondera Mark (2009, p. 108), embora alguns estudos tenham tentado definir letramento em termos de "contextos socioculturais mais amplos, a visão funcional de letramento como habilidade a ser dominada" parece ainda persistir nas políticas públicas para a educação. $\mathrm{O}$ autor acrescenta que mesmo documentos oficiais recentes não costumam considerar o letramento como uma prática crítica.

No Brasil, as OCEM-LE (BRASIL, 2006) introduziram as noções e teorias dos estudos sobre novos letramentos no ensino de inglês como LE, advogando em favor da urgente necessidade de reformulação das práticas educacionais em nossa sociedade e vêm influenciando muitas pesquisas sobre as práticas de letramento no ensino de inglês, atualmente.

Conhecer as práticas tradicionais de letramento e reconhecer suas origens é um primeiro passo para uma possível mudança pedagógica na sala de aula de inglês e para novos rumos na pesquisa sobre o tema. Este texto, portanto, objetivou introduzir as noções e práticas defendidas pelas teorias dos novos letramentos para, assim, contribuir para que mais professores e pesquisadores as utilizem em suas salas de aula e como foco de suas pesquisas, iluminando o caminho para uma desejada mudança no ensino de LE.

\section{Referências}

BARROS, E. M. D. Gêneros textuais e práticas de letramento: a temporalidade verbal no gênero crítica cinematográfica. Revista Brasileira de Linguistica Aplicada, Belo Horizonte, v. 9, n. 1, p. 177-200, 2009.

BARTON, D. Literacy: An introduction to the ecology of written language. Oxford: Blackwell, 1994.

BAYNHAM, M.; PRINSLOO, M. Introduction: the future of literacy studies. In: BAYNHAM, M.; PRINSLOO, M. (Eds.). The future of literacy studies. London: Palgrave, 2009. p. 1-20. 
BRANDT, D.; CLINTON, K. Limits of the local: expanding perspectives on literacy as a social practice. Journal of Literacy Research, v. 34, n. 3, p. 337 356, 2002.

BRASIL. Secretaria de Educação Básica. Orientações curriculares para o ensino médio: linguagens, códigos e suas tecnologias - conhecimentos de línguas estrangeiras. Brasília: Ministério da Educação; Secretaria de Educação Básica, 2006. Disponível em: <http://portal.mec.gov.br/seb/arquivos/ pdf/book_volume_01_internet.pdf $>$. Acesso em: 6 fev. 2008.

BRASIL. Conselho Nacional de Trânsito - CONTRAN. Manual brasileiro de sinalização de trânsito. v. 2. Sinalização vertical de advertência. Brasília: Contran, 2007. Disponível em: <http://www.dnit.gov.br/rodovias/ operacoes-rodoviarias/prosinal/19-manual-vol-ii-sinalizacao-vertical-deadvertencia.pdf>. Acesso em: 15 dez. 2010.

CASTELL, S. de; LUKE, A.; MacLENNAN, D. On defining literacy. In: CASTELL, S. de; LUKE, A.; EGAN, K. (Eds.). Literacy, society, and schooling: A reader. Cambridge: Cambridge University Press, 1986. p. 3-14.

COPE, B.; KALANTZIS, M. (Eds.). Multiliteracies: Literacy learning and the design of social futures. London: Routledge, 2000.

DUBOC, A. P. M. Redesenhando currículos de língua inglesa em tempos globais. Revista Brasileira de Linguística Aplicada, v. 11, n. 3, p. 727-745, 2011.

GEE, J. P. Social linguistics and literacies: Ideologies in discourses. 3. ed. London: Routledge, 2008.

HEATH, S. B. What no bedtime story means: Narrative skills at home and school. Language in Society, v. 11, p. 49-76, 1982.

HEATH, S. B. Ways with words: Language, life, and work in communities and classrooms. Cambridge: Cambridge University Press, 1983.

JORDÃO, C. M.; MATTTOS, A. M. A.; GATTTOLIN, S. R. B. Abordagem comunicativa, pedagogia crítica, letramento e letramento crítico: brasas para a mesma sardinha? In: CONGRESSO INTERNACIONAL DA ASSOCIAÇÃO BRASILEIRA DE ESTUDOS CANADENSES, 11., 2011, Salvador. Caderno de Resumos... Salvador: ABECAN/UFBA, 2011. 
LANKSHEAR, C.; KNOBEL, M. New literacies: Changing knowledge and classroom learning. Buckingham: Open University Press, 2003.

LANKSHEAR, C.; SNYDER, I.; GREEN, B. Teachers and technoliteracy: managing literacy, technology and learning in schools. St. Leonards: Allen \& Unwin, 2000.

LARSON, J.; MARSH, J. Making literacy real: Theories and practices for learning and teaching. London: Sage Publication, 2005.

LEMKE, J. L. Metamedia literacy: Transforming meanings and media. In: REINKING, D. et al. (Eds.). Literacy for the $21^{\text {st }}$ Century: technological transformation in a post-typographic world. Hillsdale, NJ: Erlbaum, 1998. Disponível em: <http://academic.brooklyn.cuny.edu/education/jlemke/ reinking.htm>. Acesso em: 9 fev. 2007.

MACIEL, R. F. Globalização, reformas educacionais e ensino de línguas: colaboração de pesquisa Brasil/Canadá. Interfaces Brasil/Canadá, Rio de Janeiro, v. 12, p. 253-270, 2011.

MARCUSCHI, L. A. Gêneros textuais: definição e funcionalidade. In: DIONÍSIO, A. et al. (Org.). Gêneros textuais e ensino. Rio de Janeiro: Lucerna, 2007. p. 19-36.

MARK, R. Exploring ways of promoting an equality discourse using nontext/creative approaches for learning in the everyday lives of adult literacy learners. In: MATTOS, A. M. A. (Ed.). Narratives on teaching and teacher education: An international perspective. New York: Palgrave, 2009. p. 107122.

MATTOS, A. M. A. O ensino de inglês como língua estrangeira na escola pública: novos letramentos, globalização e cidadania. 2011a. Tese (Doutorado em Letras - Estudos Linguísticos e Literários em Inglês) - Universidade de São Paulo, São Paulo.

MATTOS, A. M. A. Novos letramentos, ensino de língua estrangeira e o papel da escola pública no século XXI. Revista X, v. 1, p. 33-47, 2011 b.

MATTOS, A. M. A. Letramento crítico na escola pública: uma experiência na formação continuada de professores de inglês como língua estrangeira. 
In: DUTRA, D. P.; MELLO, H. R. (Orgs.). Educação continuada: diálogos entre ensino, pesquisa e extensão. Campinas: Pontes; Belo Horizonte: Faculdade de Letras, 2013. p. 21-76.

MATTOOS, A. M. A.; VALÉRIO, K. M. Letramento crítico e ensino comunicativo: lacunas e interseções. Revista Brasileira de Linguística Aplicada, v. 10, n. 1, p. 135-158, 2010.

MONTE MÓR, W. M. Foreign languages teaching, education and the new literacies studies: expanding views. In: GONÇALVES, G. R.; ALMEIDA, S. R. G.; PAIVA, V. L. M. O.; RODRIGUES-JÚNIOR, A. S. (Orgs.). New challenges in language and literature. Belo Horizonte: FALE/UFMG, 2009. p. 177-189.

NORTON, B. Critical literacy and international development. Critical Literacy: Theories and Practices, v. 1, n. 1, p. 6-15, 2007. Disponível em: <http://www.criticalliteracy.org.uk/images/journal/v1issue1/ norton.pdf>. Acesso em: 22 maio 2008.

ROJO, R. H. R. A concepção de leitor e produtor de textos nos PCNs: "ler é melhor do que estudar". In: FREITAS, M. T. A.; COSTA, S. R. (Orgs.). Leitura e escrita na formação de professores. São Paulo: Musa; UFJF; INEP-COMPED, 2002. p. 31-52.

SOARES, M. Letramento: um tema em três gêneros. 2. ed. Belo Horizonte: Autêntica, 1998.

STREET, B. Literacy in theory and practice. Cambridge: Cambridge University Press, 1984.

STREET, B.; LEFSTEIN, A. Literacy: an advanced resource book. London; New York: Routledge, 2007.

Recebido em: 09/01/2014 Aceito em: 30/05/2014 